\title{
Immunostimulants in the prevention of respiratory infections
}

Article in International Journal of Biotechnology · January 2007

DOI: $10.1504 / I J B T .2007 .014245$

CITATIONS

2

4 authors, including:

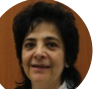

\section{Blanca Del-Rio-Navarro}

Hospital Infantil de México Federico Gómez 277 PUBLICATIONS 3,309 CITATIONS

SEE PROFILE
READS

213

Some of the authors of this publication are also working on these related projects:

Project

Mexican Guidelines on the Diagnosis and Treatment of Urticaria 2014 View project

Project

National Mexican Guideline on Asthma View project

\section{Sandra Gonzalez-Diaz}

Universidad Autonoma de Nuevo Leon 142 PUBLICATIONS 969 CITATIONS

SEE PROFILE 


\title{
Immunostimulants in the prevention of respiratory infections
}

\section{Blanca E. Del-Rio-Navarro*}

Department of Allergy and Paediatric Immunology, Hospital Infantil de Mexico Federico Gomez, Mexico City, CP 06720, Mexico

Fax: +52-55-5761-0947

E-mail: blancadelrio@yahoo.com.mx

${ }^{*}$ Corresponding author

\section{Sandra González-Díaz}

Department of Allergy and Immunology,

Hospital Universitario José Eleuterio González,

Monterrey, CP 64460 Mexico

Fax: +83-48-24-59

E-mail: sgonzalezdiaz@yahoo.com

E-mail: sgonzalezdiaz@alergiashu.org

\section{Alberto José Escalante-Domínguez}

General Director of Hospital General de Playas de Rosarito, Tijuana, Baja California, Mexico

Fax: 66-46-84-06-40

E-mail: escalante@cmica.org

\section{Virginia Blandón-Vijil}

Department of Allergy and Paediatric Immunology, Hospital Infantil de Mexico Federico Gomez, Mexico City, CP 06720, Mexico

Fax: +52-55-5761-0947

E-mail: blandonv@prodigy.net.mx

\begin{abstract}
Immunomodulation promises to be an effective prophylactic and therapeutic modality for chronic and recurrent respiratory infections. As opposed to vaccines, the term Immunostimulant (IS) refers to a compound that produces a state of non-specific immunity. Most IS are oral formulations of bacterial lysates that have been used in clinical practice for decades. One of the main obstacles in the development of immunostimulants is the poor understanding of the mechanism of action. Except for some compounds the mechanism of action of bacterial products is not well understood. Some appear to act through activation of monocytic cells and macrophages and enhancement of polyclonal proliferation of B cells. In general, the use of IS results in beneficial clinical outcome but the quality of some clinical trials for preventing Acute Respiratory Tract Infections (ARTIs) must be improved. In pediatric
\end{abstract}


population the use of IS for the prevention of ARTIs needs to be limited to children with high susceptibility to ARTIs or overexposed children, while in adults it must be indicated for patients with Chronic Obstructive Pulmonary Diseases (COPD) at high risk of exacerbation.

Keywords: Immunostimulant (IS); mechanism of action; Acute Respiratory Tract Infections (ARTIs); Chronic Obstructive Pulmonary Diseases (COPD); clinical trials.

Reference to this paper should be made as follows: Del-Rio-Navarro, B.E., González-Díaz, S., Escalante-Domínguez, A.J. and Blandón-Vijil, V., (2007) 'Immunostimulants in the prevention of respiratory infections', Int. J. Biotechnology, Vol. 9, Nos. 3/4, pp.246-260.

Biographical notes: Blanca E. Del-Rio-Navarro is the Chief of Pediatric Allergy and Immunology Department of Hospital Infantil de Mexico Federico Gomez as well as the Programme Director of Pediatric Allergy and Immunology at Universidad Nacional Autonoma de Mexico. She is a reviewer from Cochrane Group for respiratory infections since 2004 and she has published about 80 international papers on allergy and immunology.

Sandra González Díaz is the Chief of Allergy and Immunology Department of Hospital Universitario José Eleuterio Gonzalez as well as the President of Colegio Mexicano de Imunologia Clinica y Alergia since 2005. She has published 117 national and international publications papers on Allergy and Immunology. Currently, she is the Programme Director of Allergy and Immunlogy at Medical School at Universidad Autónoma de Nuevo León.

Alberto José Escalante Domínguez is a Pediatric Allergist, he is the actual General Director of Hospital General de Playas de Rosarito, a Public Health Hospital at Tijuana, Baja California. Baja California. Board member of Colegio Mexicano de Inmunología Clínica y Alergia since 2005.

Virginia Blandón-Vijil is a Researcher in Allergy Department at Hospital Infantil de Mexico. And also she is a Pediatric professor for interns at Hospital Infantil de Mexico Federico Gómez. Her expertise on clinical trials involves organisation, patient recruitment, data management and results publication.

\section{Introduction}

For years immunologists were trying to devise immunomodulators that could be useful for treatment of illness where there are defects in the immunity like in cases of chronic and recurrent infections, cancer, or autoimmune diseases. Immunomodulators may enhance immune response in some but decrease in other cases. The term Immunostimulant (IS), as used in this paper, refers to a compound that produces a state of non-specific immunity that contributes to enhancement of resistance to an infection or malignancy (Bomford, 1989; Hadden, 1993). On the other hand, inmunosupressors interfere in a non-specific way with the immune response, which in some cases can increase the susceptibility to infections and cancer. Nevertheless, as noted by Bomford (1989) and Hadden (1993) it is often difficult to draw a clear line between ISs and immunosuppressors. 
The main difference between an IS and a vaccine is that the latter is suppose to produce a protective immune response against a specific microorganism, which is included in the formulation either as a whole organism or a subunit thereof. Many ISs were developed in the preantibiotic era as an option to treat and prevent infectious diseases. During the first part of the 20th century the development of ISs has been ongoing in parallel with that of vaccines, that is, their empirical use preceded the understanding of the mechanism of action. Most of the registered ISs currently employed for the prevention of Acute Respiratory Tract Infections (ARTIs) are bacteria-derived products. Table 1 lists the common IS formulations for ARTIs prevention.

\section{Mechanism of action of IS}

The immune system is an intricate network of cells and a great variety of signalling molecules. The regulation of the immune system depends on the interaction points between cells and soluble substances that define the immune response (Bomford, 1989; Hadden, 1993).

Table 1 Most common ISs for prevention of acute respiratory infections

\begin{tabular}{lll}
\hline Trade name & Common name & Active entity \\
\hline Adimod & Pidotimod & Pidotimod \\
Biostim & RU41740 & $\begin{array}{l}\text { Glycoprotein and membranes of } \\
\text { Klebsiella pneumoniae }\end{array}$ \\
Broncho-Vaxom & OM-85 & Lyophilized bacterial lysates \\
Decaris & Levamisole & Levamisole \\
Echinacea & Echinacea purpurea, & Extract of Echinacea purpurea \\
Immunoferon, Inmunol & AM3 & Glycophosphopeptical \\
IRS 19 & Not available & Bacterial lysates \\
Ismigen & Not available & Bacterial lysates \\
Lantigen B & Not available & Bacterial antigens \\
Leucotrofina, Leucogen & Thymomodulin & Thymus extract \\
Luivac & LW50020 & Bacterial antigen \\
Munostin & Not available & Bacterial corpses and lysates \\
Not available & SLO4 & Bacterial extracts \\
Paspat & LW50020 & Autolysate mixture of bacterial \\
autigens for parenteral application
\end{tabular}


Except for the compound RU41740, the mechanism of action of bacterial products is not well understood, as their chemical nature has not been fully elucidated. RU41740 is an organic extraction of Klebsiella pneumoniae, it consists of two repetitive glycoprotein subunits: P1 from bacterial capsule and F1 from external bacterial membrane. It has been suggested that RU41740 induces activation of macrophages as well as polyclonal activation of B cells (Boissier, 1988; Chaumet and Boissier, 1988). Vacheron et al. (1989) and Miller et al. (2005) reported that Lipopolysaccharide (LPS) fraction F1 acts on LPS-receptors TLR4-MD2-CD14.

D53 contains proteoglycans from Klebsiella pneumoniae combined with ribosomal fractions from four different bacterial strains. D53 stimulates polymorphonuclear cells and macrophages, which leads to increased phagocytosis and proinflammatory cytokines. Also, ribosomal fractions induce formation of specific antibody-forming B cells, but response on T-cell has not been reported (Bene and Faure, 1997; Clot, 1997).

Another IS, OM-85, acts on macrophages and monocytic cells through the increase of intracellular calcium, glucose-regulated protein 7815 and c-fos/serum response element protein. These secondary messengers induce expression of pro-inflammatory interleukins IL-1a, IL-6, IL-8, and tumor necrosis factor-alpha (Broug-Holub et al., 1995; Keul et al., 1996). Other investigators reported that OM-85 BV induces nitric oxide and oxygen radicals in phagocytic cells (Broug-Holub et al., 1995; Lusuardi et al., 1993). In addition, the upregulation of adhesion molecules has been described by Marchant and Goldman (1996) and Jacquier-Sarlin et al. (1996). Humans who received OM-85 BV displayed enhanced cellular immune responses (Girard and Fleury, 1979; Maestroni and Losa, 1984); increase in secretory IgA (Emmerich et al., 1990; Lusuardi et al., 1993); serum IgA (Cvoriscec et al., 1989); serum IgG and IgM (Puigdollers et al., 1980); and activated phagocytic cells (Emmerich et al., 1990; Lusuardi et al., 1993).

The IS based on thymic extracts has not been well characterised, but their effect appears to be mainly on T-cell response. The use of thymic extract has been banned by the World Health Organization (WHO fact sheet 113, 2005) because of the risk of spongiform encephalopathy.

One of the main obstacles in the development of ISs is the poor understanding of the mechanism of action. It has been particularly challenging to identify a receptor or molecular target that would be associated with prevention of ARTIs. However, we have a better knowledge of synthetic ISs. For instance, tucaresol acts by forming covalent Schiff bases between ligands on APC and T-cells. Schiff bases are an essential element for providing a costimulatory signal to T-cell and increasing the synthesis of IL2 and gamma IFN (Rhodes, 1996). The imidazolic compounds, imiquimod and resimiquimod appear to act through Toll Like Receptor 7 (TLR 7) and TLR 8 (Spaner et al., 2005; Weeratna et al., 2005). Other functions of levamisole and pidotimod have also been described. For example, levamisole enhances cellular immunity by enhancing in vitro T-cell proliferation as induced by antigens and mitogens (Amery and Bruynseels, 1992; Van Wauwe and Janssen, 1991) This action is mediated by a metabolite called OMPI (dl-2-oxy-3-(2-mercaptoethyl)-5 phenylimidazolidine (Hanson and Heidrick, 1991) Yet, the use of levamisole should be restricted because of the risk of agranulocytosis (Symoens et al., 1978) Pidotimod is another imidazolic compound that acts by enhancing cellular immunity (Benetti et al., 1994; Coppi and Manzardo, 1994). Thus, despite intensive research on immune function of IS we still do not know what is the ultimate mechanism of action either for bacterial IS or synthetic IS. 
Table 2 Toll-like receptors and their ligands

\begin{tabular}{ll}
\hline Receptor & Ligand or pathogen-associated molecular pattern (PAMP) \\
\hline TLR 1 & Triacyl lipoproteins \\
TLR 2 & Lipoproteins; gram positive peptidoglycan; lipoteichoic acids; fungi; zymosan \\
TLR 3 & Double-stranded RNA (as found in certain viruses) \\
TLR 4 & LPS (endotoxin) \\
TLR 5 & Flagellin \\
TLR 6 & Diacyl lipoproteins, peptidoglycan \\
TLR 7 & Small synthetic compounds; single-stranded RNA \\
TLR 8 & Small synthetic compounds; single-stranded RNA \\
TLR 9 & Unmethylated CpG DNA \\
TLR 10 & Unknown \\
TLR 11 & Proteins expressed by several infectious protozoa \\
\hline
\end{tabular}

\section{The epidemiology of ARTIs}

ARTIs are still an important health and economic burden in the world. According to WHO (1998) ARTIs are the leading cause of morbidity accounting for $20 \%$ of medical consultations, $30 \%$ of lost days to work, and $75 \%$ of antibiotic prescriptions. ARTIs are responsible for most sick days at school amongst children (Haskins and Kotch, 1986) and parental absenteeism from work (Bell et al., 1989).

Community health studies in developed countries have provided basic information on the incidence of ARTIs. In the survey conducted in Tecumseh, Michigan, the annual incidence of ARTIs per person between 1965 and 1971, was 6.1 in children less than one year old; 5.7 in children aged from one to two years; 4.7 in children aged from three to four years; 3.5 in children aged from five to nine years; 2.7 in children aged from 10 to 14 years; 2.4 in 15-19-year-old; and from 2.8 to 1.3 in the adults (20 to $>60$ years) (Monto and Sullivan, 1974). In the second report of the Tecumseh study, which covered two phases comprising a period of 11 years (1965-1971 and 1976-1981), the mean annual number of ARTIs was 4.9 in the group from zero to four years; 2.8 in the group from 5 to 19 years; 2.2 in the group from 20 to 39 years; and 1.6 in the group $\geq 40$ years (Monto and Sullivan, 1993). Table 3 and Figure 1 summarise the incidence of ARTIs found in the Tecumseh study. The BOSTID study in Africa, Asia and Latin America surveyed children from zero to 59 months of age (Selwyn, 1990). The incidence rate in six community-based studies ranged from 12.7 to 16.8 ARTIs per 100 child-weeks and the incidence of lower ARTIs was from 0.2 to 0.4 per 100 child-weeks.

In Mexico, the children raised at home had six ARTIs each year, with a median of 40 sick days per year, while children attending the day-care centres had 14 ARTIs per year with a median of 74 sick days (Flores-Hernandez et al., 1999). Another study in Mexico by Nandi-Lozano et al. (2002) found that the incidence of ARTIs in children attending the day-care centres was 10.3 per child/year.

Viruses are the main etiological agents of ARTIs in children at day-care centres and in the community. The most common virus isolates are rhinovirus, respiratory syncytial virus, parainfluenza virus and adenovirus (Denny et al., 1986; Flores-Hernandez et al., 
1999; Monto and Sullivan, 1974; Monto and Sullivan, 1993; Nandi-Lozano et al., 2002; Selwyn, 1990). So, in our opinion, if an IS is to prevent ARTIs, it should prevent the viral ARTIs and not just the bacterial infections, especially against bacteria contained in IS formulas. In the contrary case IS will not be much different from vaccines.

Table 3 The incidence of ARTIs by age groups as found in the Tecumseh study

\begin{tabular}{|c|c|c|c|}
\hline \multicolumn{2}{|c|}{ First phase $(1965-1971)^{a}$} & \multicolumn{2}{|c|}{ Second phase (1965-1971) and (1976-1981) } \\
\hline Percentage & Age group & Percentage & Age group \\
\hline 6.1 & 0 to 11 months & 4.9 & 0 months to 4 years \\
\hline 5.7 & $1-2$ years & 2.8 & $5-19$ years \\
\hline 4.7 & $3-4$ years & 2.2 & 20-39 years \\
\hline 3.5 & 5-9 years & 1.6 & $\geq 40$ years \\
\hline 2.7 & $10-14$ years & & \\
\hline 2.4 & $15-19$ years & & \\
\hline 2.8 to 1.3 & Adults 20 to $>60$ years & & \\
\hline
\end{tabular}

${ }^{a}$ Total period of 6 years. Monto and Sullivan (1974).

${ }^{\mathrm{b}}$ Total period of 11 years. Source:. Monto and Sullivan (1993).

Figure 1 Incidence of ARTIs found in the Tecumseh study

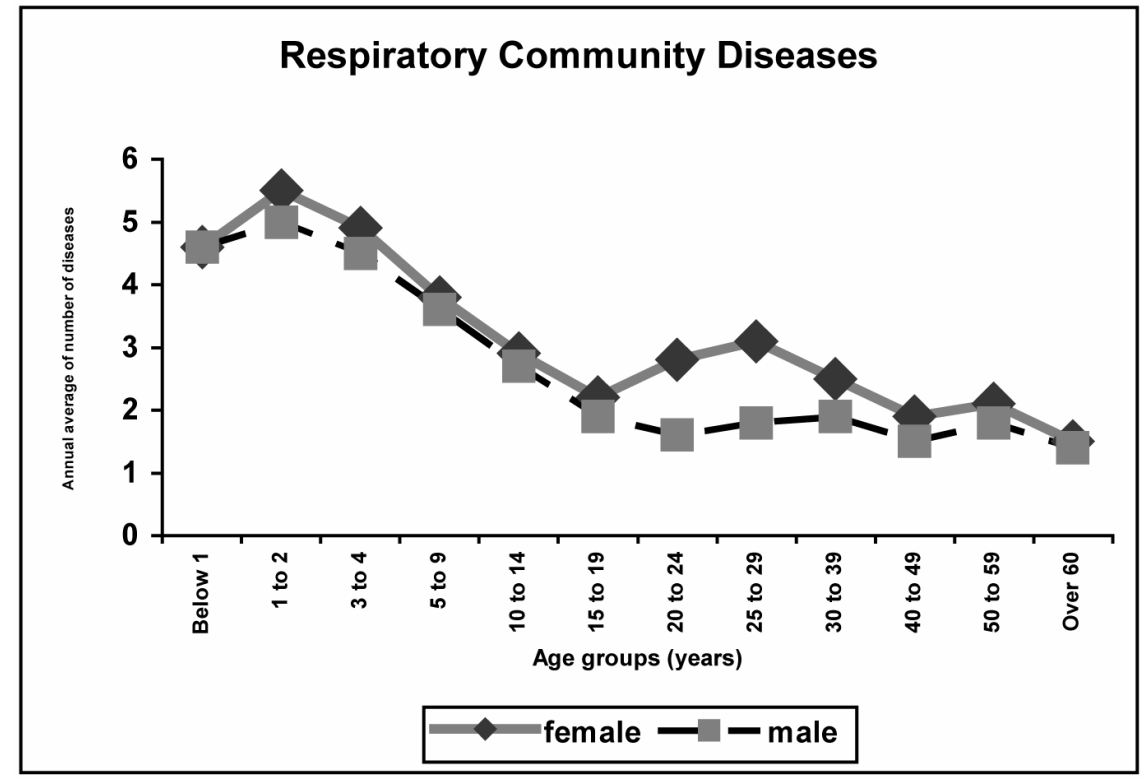

The use of ISs should be appropriate when the number of ARTIs in the target group is higher than the normal incidence in the same age group. Based on our clinical experience in controlled and uncontrolled trials, as well as from general clinical practice, it will be difficult to diminish the number of ARTIs below the number in a normal healthy group. 


\section{Safety}

\subsection{Children}

The Cochrane review on the use of IS for prevention of ARTIs in children provides data on adverse events revealed during clinical trials. Most of the trials reported a low incidence of adverse events or no adverse events at all. We observed that most frequent adverse events were gastrointestinal complaints such as nausea, vomit, discomfort and diarrhoea, and skin disorders such as rash, urticaria and pruritus (Berber et al., 2005).

According to an expert consensus, the incidence of adverse events in OM-85 BV clinical trials is $3-4 \%$ of the treated children. The most frequent adverse events were gastrointestinal complaints (gastric upset, abdominal pain, diarrhoea, nausea, vomit, and appetite loss) and cutaneous alterations (rash, erithema, pruritus). In the pharmacovigilance survey of OM-85 BV the most frequent complaints were fever, diarrhoea, rash, urticaria, abdominal pain, asthma, pruritus, and rhinitis. The risk of an autoimmune disease was pronounced to be minimal (Aiuti, 1993).

\subsection{Adults}

In adult patients with Chronic Obstructive Pulmonary Diseases (COPD), the bacteria-derived IS may cause adverse reaction in $3.3 \%$ of treated population which includes itching and cutaneous eruptions. $8 \%$ of the patients presented low urinary tract symptoms. The incidence of other complaints was not statistically different from the placebo group (Steurer-Stey 2004).

The systematic review of OM-85 BV revealed that adverse events were mild and similar in frequency to control population (Sprenkle et al., 2005). The most common reported adverse events were headache and gastrointestinal symptoms.

The search of the medical literature identified only two serious adverse event cases associated with IS; one case of bullous pemphigoid (an autoimmune disease associated with autoantibodies directed against the hemidesmosomal antigens BP230 and B180) associated with RU41740 (Chaby et al., 2004), and one case of another rare autoimmune disorder, tubulointerstitial nephritis, associated with D53 (Litwin et al., 2001).

\section{Clinical efficacy}

\subsection{Children}

All IS claim to be effective. Unfortunately, many of them failed to show efficacy in randomised, placebo-controlled trials. There are several reviews and meta-analyses of the efficacy of IS for the prevention of ARTIs in children and for the prevention of symptom exacerbations in patients with chronic bronchitis or COPD. The first review in 2001 by Berber et al. (2001) tried to compile and combine the results of randomised placebo-controlled clinical trials in the prevention of respiratory tract infections in children using IS. References of ISs (registered as products for ARTIs prevention) and ARTIs were searched and reports of randomised controlled clinical trials on the prevention of ARTIs in children were selected. Data sources were Medline, EMBASE and Cochrane Acute Respiratory Infection Group's register. The number of ARTIs was extracted as mean and Standard Deviation (SD) for the placebo and treated group. 
Among IS, D53 $(n=2)$, LW50020 $(n=2)$, OM-85 BV $(n=9)$, pidotimod $(n=6)$, RU41740 $(n=4)$ and Thymomodulin $(n=4)$ had randomised, controlled trials $(n=27)$. However, only 20 trials reported the number of ARTIs and only 16 reported mean and SD data. The outcome of each trial was expressed as the percent value in comparison to the placebo group considered as $100 \%$. The overall effect of IS in prevention of ARTIs was $-42.6 \%$ (95\% CI $-45.2 \%,-40.1 \%)$, meaning that treated group had about $60 \%$ of the ARTIs incidence in relation to the placebo group. The quality of most trials was low, but those with higher Jadad's score were indicative of better efficacy (Jadad et al., 1996).

D53 had two extensive reviews of its results in randomised placebo controlled and uncontrolled trials, including results from unpublished trials in children and adults (Boyle et al., 2000). In a three-month period the use of D53 produced a reduction of $1.23 \pm 0.45$, while in a six-month period the reduction was $1.51 \pm 0.31$ (Bellanti et al., 2003).

A comparative meta-analysis by De la Torre et al. (2005) includes the most representative, commercially available IS for ARTIs in children. The study evaluated the effect as the total reduction in number of ARTIs and percentage of reduction considering the mean ARTI number in the placebo group as $100 \%$. Only trials longer than three months were considered and the effect was proportional to six months. The IS considered were D53, OM-85 BV, pidotimod and RU41740; the rest of the IS had no references to randomised, placebo controlled trials. The effects of each IS are listed in Table 4. D53 and OM-85 BV have shown efficacy both in terms of number and percent of ARTIs, while pidotimod had efficacy data expressed as a percent of ARTIs.

Table 4 Clinical effect of IS as a net difference in ARTIs incidence (confidence interval) compared to the mean number of ARTIs incidence in a placebo group considered as $100 \%$

\begin{tabular}{lcc}
\hline & Number of ARTIS $(95 \%$ CI $)$ & Percent of ARTIs $(95 \%$ CI) \\
\hline D53 & $-0.92(-1.46,-0.39)^{*}$ & $-31.86(-34.32,-29.40)^{*}$ \\
OM-85 BV & $-1.20(-1.70,-0.69)^{*}$ & $-39.28(-52.58,-25.98)^{*}$ \\
RU41740 & $-0.81(-2.24,+0.62)$ & $-27.60(-73.88,+18.69)$ \\
Pidotimod & $-0.82(-1.84,+0.21)$ & $-31.26(-42.51,-20.01)^{*}$ \\
\hline
\end{tabular}

$* p<0.05$.

A Cochrane systematic review on the use of IS for preventing ARTIs in children is in preparation (Berber et al., 2005). The review considers only randomised (or quasi-randomised), placebo-controlled trials. All kinds of medications have been included. D53 had 17 trials, but six trials were reported only in reviews of the product (Boyle et al., 2000; Bellanti et al., 2003). The duration of eight D53 trials was less than six months and nine trials had duration of six months. In all D53 trials the description of the methodology was not clear and different routes of administration were used (nasal spray or oral). OM-85 BV had 12 trials, all published in journals, but only four were in journals with substantial impact factor (Collet et al., 1993; Gutiérrez-Tarango and Berber, 2001; Jara-Perez and Berber, 2000; Schaad et al., 2002) Four OM-85 trials were of high quality (Collet et al., 1993; Del Rio Navarro et al., 2003; Gutiérrez-Tarango and Berber, 2001; Jara-Perez and Berber, 2000) and in the remaining, the methodology was not very clear. Ten OM-85 trials had a duration of six months and two were longer than 
six months. The main end-points were the number of ARTIs during the study period, expressed as a mean and standard error or SD. The outcome was analysed as mean number of ARTIs by group (raw data) and as percentage of ARTIs in the treated groups and compared to placebo, which is considered as $100 \%$. Up to this time only 34 out of 57 randomised, placebo controlled trials had mean number of ARTIs or frequency tables from which means can be deduced. About 23 out of 34 studies showed reduction of ARTIs both as total numbers and as percentage of ARTIs. The effect on the total number of ARTIs was an absolute reduction [-1.27 (95\% CI -1.58, -0.97)] as well as reduction in percentage of ARTIs [-39.68\%; 95\% CI $(-47.27 \%,-32.09 \%)]$. When results are expressed as absolute number of ARTIs, the data were heterogeneous $\left(\chi^{2}=579.87\right.$, $p<0.00001)$. The use of percentage values reduced the heterogeneity $\left(\chi^{2}=185.76\right.$, $p<0.00001)$. The main source of heterogeneity was the mean number of ARTIs in the control group compared to absolute number of ARTIs (Pearson correlation $=-0.672$, $p<0.001)$ or mean difference in the percentage of ARTIs related to the mean difference in the number of ARTIs (Pearson correlation $=-0.638, p<0.001$ ).

\subsection{Adults}

In adults the main application of IS is in prevention of exacerbations in chronic bronchitis or COPD. The use of IS for COPD is mentioned in the guidelines of management of COPD of the Global Initiative for Chronic Obstructive Lung Disease (GOLD group created by the National Heart, Lung, and Blood Institute and the World Health Organisation). (Global Initiative for Chronic Obstructive Lung Disease, 1998) Based on a single OM-85 study by Collet et al. (1997) they rank the use of IS as Type B evidence and do not recommend its regular use.

Yet, there are many other studies on the use of IS for the management of COPD. For instance, there is a systematic review on the use of bacterial IS in COPD (Steurer-Stey et al., 2004) 13 trials were identified: 10 with OM-85 BV, two with LW50020 and one with SL-04. Only three trials reported the number of exacerbations from which it was possible to calculate the relative risk of one exacerbation as 0.66 (95\% CI, 0.41, 1.08), $p>0.05$. Yet the analysis of other outcomes showed significant $(p<0.05)$ observer-assessed improvement of symptoms, patient-assessed improvement, and a short average duration of an exacerbation.

Other reviews dealt with a single type of IS. An OM-85 BV review found 13 randomised placebo controlled trials on COPD and included three in the metaanalysis showing a non-statistically significant trend in favour of OM-85 BV (relative risk of exacerbation $0.83,95 \%$ confidence interval 0.65-1.05) (Sprenkle et al., 2005).

A systematic review of controlled trials of AM3 in patients with COPD by Reyes et al. (2004) cites nine studies. The effect of AM3 translated into a decrease in the average number of exacerbations by 0.31 units $(p<0.001 ; 95 \%$ CI $0.20-0.42)$, significant favourable differences were found in the average length of the exacerbations and the average length of the antibiotic treatment used for the exacerbations $(p<0.001)$.

On the other hand, Dahan et al. (1986) in an early review on the effect of RU41740 (then named C1740) in chronic bronchitis failed to show benefits to the patients. Only four out of eight trials had positive results; the negative results were attributed to the low power of sample size.

IS have been also used to prevent sinusitis (Gomez Barreto et al., 1998; Heintz et al., 1989; Zagar and Lofler-Badzek, 1988), otitis (Giovannini et al., 2000; Mora et al., 
2002; Renzo et al., 2004) and occupational respiratory disease in factory workers (Carmona-Ramirez et al., 2002; De Marco et al., 1984). Although provocative, theses uses must have further randomised placebo controlled trials to establish the clinical benefit. Other important point to stress out is that, so far, only one trial has demonstrated effective protection against viral ARTIs as supported by viral culture (Aymard et al., 1994).

\section{Discussion}

The use of IS is not uncommon in some countries in Europe and America as a means of reducing the incidence of ARTIs in children and number and severity of COPD in adult patients. Yet, as the mechanisms of action are not completely understood and the clinical evidence is not well established, their utility remains controversial. The lack of enthusiasm, particularly among doctors educated in Anglo-Saxon countries, in embracing this kind of medication may have attributed, at least in part, to the deficiencies in the knowledge of mechanism of IS.

The quality of IS clinical trials, in general, is poor, although some of the trials conducted lately have improved. The most common problems in children and adult trials are the failure to select precise endpoints; lack of proper control; poor selection criteria; ill-defined standard operating definitions and proceedings; small sample size; and inapt explanations for dropouts and adverse events. All these deficiencies in the clinical protocol resulted in low power of data to reveal the differences between medication and placebo groups.

Trials in children have demonstrated that the efficacy of IS to prevent $\geq 1$ incident is not reliable, but improves with $\geq 2$ and $\geq 3$ incidents (Del Rio Navarro et al., 2003; Gutierrez-Tarango and Berber, 2001; Jara-Perez and Berber, 2000). We believe that the failure to show significance in COPD is due to reliance on measuring $\geq 1$ incident as dichotomous outcome data. We believe that the number of exacerbations (mean and SD) would be a better measure (scaled data). It would be convenient to explore the relative risk of $\geq 2, \geq 3$ exacerbations in the COPD trials (Del Rio Navarro et al., 2004).

The results of clinical trials have shown that the reduction in the incidence of ARTIs in children and the reduction of exacerbations in COPD patients are real possibilities. Yet, IS protective effect would be noticeable in patients who experience a large number of ARTIs as compared to their normal peers. Therefore, in pediatric population the use of IS for the prevention of ARTIs must be limited to children with proven high susceptibility to ARTIs or overexposed children, while in adults it must be limited to patients with high risk of exacerbation of COPD.

The quality of the IS trials for preventing ARTIs needs to be improved as well as reporting of the results and adverse events (Begg et al., 1996; Collet, 1992; Valleron and Grimfeld, 1992). As a matter of public interest larger clinical trials sponsored by health authorities are desirable to establish the real effect of each individual IS. Additional indications to be explored in adults and children are the prevention of viral ARTIs (including asthma patients) and the prevention of recurrent otitis.

The mechanism of action of the bacterial and synthetic IS needs to be clarified, particularly the site of action or receptor involved, in order to create specific agonists and antagonists for clinical application. For instance, we need to identify active ingredients in bacterial extracts and their affinity receptors in order to create new synthetic entities. 
To explore other possible paths is to seek different agonists and antagonists of TLR or to create new series of molecules capable of forming Schiff bases on the surface of immune cells as suggested by Rhodes (2002).

Some years ago, Hadden (1993) stated that the use of ISs was something like 'try to fix a TV set by kicking at it'. Currently, we know that this proverbial 'kick' can fix the $\mathrm{TV}$ and we are about to open it with proper tools to figure out what exactly happened.

\section{References}

Aiuti, F. (1993) 'Can immunostimulating bacterial extracts induce auto-immune disease? in immunomodulation in chronic respiratory disease', European Respiratory Society Annual Congress, Firenze.

Akira, S. and Hemmi, H. (2003) 'Recognition of pathogen-associated molecular patterns by TLR family', Immunology Letters, Vol. 85, No. 2, pp.85-95.

Amery, W.K. and Bruynseels, J.P. (1992) 'Levamisole, the story and the lessons', International Journal of Immunopharmacology, Vol. 14, No. 3, pp.481-486.

Aymard, M., et al. (1994) 'Epidemiology of viral infections and evaluation of the potential benefit of OM-85 BV on the virologic status of children attending day-care centers', Respiration, Vol. 61, No. 1, Supplement, pp.24-31.

Begg, C., Cho, M., Eastwood, S., Horton, R., Moher, D., Olkin, I., Pitkin, R., Rennie, D., Schulz, K.F., Simel, D. and Stroup, D.F. (1996) 'Improving the quality of reporting of randomized controlled trials. The CONSORT statement', JAMA, Vol. 276, No. 8, pp.637-639.

Bell, D.M., et al. (1989) 'Illness associated with child day care: a study of incidence and cost', American Journal of Public Health, Vol. 79, No. 4, pp.479-484.

Bellanti, J., Olivieri, D. and Serrano, E. (2003) 'Ribosomal immunostimulation: assessment of studies evaluating its clinical relevance in the prevention of upper and lower respiratory tract infections in children and adults', Biodrugs, Vol. 17, pp.355-367.

Bene, M.C. and Faure, G.C. (1997) 'From Peyer's patches to tonsils. Specific stimulation with ribosomal immunotherapy', Drugs, Vol. 54, Supplement 1, pp.24-28.

Benetti, G.P., Fugazza, L., Stramba, B.M., Montalto, F., Bombelli, G., La Vecchia, G., Illeni, M.T. and Uslenghi, C. (1994) 'Ex vivo evaluation of pidotimod activity on cell-mediated immunity', Arzneimittelforschung, Vol. 44, No. 12A, pp.1476-1479.

Berber, A. and Del-Rio-Navarro, B. (2001) 'Compilation and meta-analysis of randomized placebo-controlled clinical trials on the prevention of respiratory tract infections in children using immunostimulants', Journal of Investigation Allergol Clinical Immunology, Vol. 11, No. 4, pp.235-246.

Berber, A., Del-Rio-Navarro, B.E., Flenady, V. and Sienra-Monge, J.J.L. (2005) 'Immunostimulants for preventing respiratory tract infection in children (Protocol for a Cochrane Review)', The Cochrane Library, No. 2, Oxford: Update Software.

Boissier, M.C. (1988) 'Experimental immunopharmacology of RU 41740', La Presse Medicale, Vol. 17, No. 28, pp.1426-1429.

Bomford, R. (1989) 'Immunological adjuvants', in M.M. Dale and J. Foreman (Eds). Textbook of Immunopharmacology, 2nd Edition, Oxford: Blackwell Scientific Publications, pp.320-323.

Boyle, P., Bellanti, J.A. and Robertson, C. (2000) 'Meta-analysis of published clinical trials of a ribosomal vaccine (Ribomunyl R) in prevention of respiratory infections', Biodrugs, Vol. 14, pp.389-408.

Broug-Holub, E., Persoons, J.H., Schornagel, K. and Kraal, G. (1995) 'Changes in cytokine and nitric oxide secretion by rat alveolar macrophages after oral administration of bacterial extracts', Clinical Experimental Immunology, Vol. 101, No. 2, pp.302-307. 
Carmona-Ramirez, M.A., Alvarez-Gomez, V. and Berber, A. (2002) 'Use of OM-85 BV for the prevention of acute respiratory tract infections in occupational medicine', Journal of International Medical Research, Vol. 30, No. 3, pp.325-329.

Chaby, G., Dascotte-Barbeau, E., Viseux, V., Andrejak, M., Denoeux, J.P. and Lok, C. (2004) 'Pemphigoïde bulleuse sous Biostim (Glycoprotéine extraite de Klebsiella pneumoniae) [Biostim (glycoprotein extracted from Klebsiella pneumoniae)-induced Bullous pemphigoid]', Therapie, Vol. 59, No. 2, pp.270-271.

Chaumet, B. and Boissier, M.C. (1988) 'Structure and distribution of RU 41740', La Presse Medicale, Vol. 17, No. 28, pp.1423-1425.

Clot, J. (1997) 'Pharmacology of ribosomal immunotherapy', Drugs, Vol. 54, Supplement 1, pp.33-36.

Collet, J.P. (1992) 'Immunomodulators and primary prevention of respiratory infections: methodological considerations', Developments in Biological Standardization, Vol. 77, pp.159-165.

Collet, J.P., Ducruet, T., Kramer, M.S., Haggerty, J., Floret, D., Chomel, J.J. and Durr, F. (1993) 'Stimulation of nonspecific immunity to reduce the risk of recurrent infections in children attending day-care centers. The Epicreche Research Group', Pediatric Infectious Disease Journal, Vol. 12, No. 8, pp.648-652.

Collet, J.P., Shapiro, P., Ernst, P., Renzi, T., Ducruet, T. and Robinson, A. (1997) 'Effects of an immunostimulating agent on acute exacerbations and hospitalizations in patients with chronic obstructive pulmonary disease. The PARI-IS Study Steering Committee and Research Group. Prevention of Acute Respiratory Infection by an Immunostimulant', American Journal of Respiratory Critical Care Medicine, Vol. 156, pp.1719-1724.

Coppi, G. and Manzardo, S. (1994) 'Experimental immunological screening tests on pidotimod', Arzneimittelforschung, Vol. 44, No. 12A, pp.1411-1416.

Cvoriscec, B., Ustar, M., Pardon, R., Palecek, I., Stipic-Markovic, A. and Zimic, B. (1989) 'Oral immunotherapy of chronic bronchitis: a double-blind placebo-controlled multicentre study', Respiration, Vol. 55, No. 3, pp.129-135.

Dahan, R., Costantini, D., Caulin, C. and Yagello, M. (1986) 'Clinical trials with C 1740, an immunomodulator compound proposed for prevention of acute infectious exacerbations in chronic bronchitis', Experimental Clinical Pharmacology, Vol. 8, No. 1, pp.41-43.

De la Torre, G.C., Pacheco, R.A., Escalante, D.A.J. and Del Rio Navarro, B.E. (2005) 'Comparative meta-analysis of immunoestimulant agents used in pediatric patients in Mexico', Revista Alergia Mexico, pp.25-38.

De Marco, A.R., Alberdi, I. and Saguier, P. (1984) 'Estudio sobre la eficacia de un nuevo fármaco inmunobioterápico de origen bacteriano (broncho-vaxom) administrado por vía oral en la profilaxis de las infecciones respiratorias recurrentes', Acta Terapéutica, Vol. 10, pp.303-312.

Del Rio Navarro, B.E. and Escalante-Dominguez, A.J. (2004) 'Immunostimulants for chronic bronchitis/COPD', A Letter to Chest, 25 November, Available at: http://www.chestjournal. org/cgi/eletters/126/5/1645.

Del Rio Navarro, B.E., Sienra-Monge, J.J.L., Berber, A., Torres-Alcántara, S., Ávila-Castañón, L. and Gómez-Barreto, D. (2003) 'Use of OM-85 BV in children suffering from recurrent respiratory tract infections and subnormal IgG suclass levels', Allergologia Immunopathologia, Vol. 31, pp.7-13.

Denny, F.W., Collier, A.M. and Henderson, F.W. (1986) 'Acute respiratory infections in day care', Reviews of Infectious Disease, Vol. 8, No. 4, pp.527-532.

Emmerich, B., Emslander, H.P., Pachmann, K., Hallek, M., Milatovic, D. and Busch, R. (1990) 'Local immunity in patients with chronic bronchitis and the effects of a bacterial extract, Broncho-Vaxom, on $\mathrm{T}$ lymphocytes, macrophages, gamma-interferon and secretory immunoglobulin A in bronchoalveolar lavage fluid and other variables', Respiration, Vol. 57, No. 2, pp.90-99. 
Flores-Hernandez, S., Reyes-Morales, H., Perez-Cuevas, R. and Guiscafre-Gallardo, H. (1999) 'The day care center as a risk factor for acute respiratory infections', Archives of Medical Research, Vol. 30, No. 3, pp.216-223.

Giovannini, M., Fiocchi, A., Sala, M., Fontana, P., Fiori, L., Silano, M. and Baldini, G. (2000) 'Immucytal(R) in the prevention and treatment of recurrent upper respiratory tract infections in children: A randomized, placebo-controlled, double-blind study', International Journal of Immunotherapy, Vol. 16, Nos. 3/4, pp.67-75.

Girard, J.P. and Fleury, S. (1979) 'Analyze comparative du levamisole et d'un lysat bacterien sur la reponse lymphocytaire in vitro', Medicine and Hygiene, Vol. 37, pp.2519-2526.

Global Initiative for Chronic Obstructive Lung Disease (1998) 'Global strategy for the diagnosis, management, and prevention of chronic obstructive pulmonary disease 2004. (Based on an April 1998 NHLBI/WHO Workshop)', Available at: http://www.goldcopd.org/.

Gomez Barreto, D., De la Torre, C., Alvarez, A., Faure, A. and Berber, A. (1998) 'Safety and efficacy of OM-85-BV plus amoxicillin/clavulanate in the treatment of subacute sinusitis and the prevention of recurrent infections in children', Allergologia et Immunopathologia, Vol. 26, No. 1, pp.17-22.

Gutiérrez-Tarango, M.D. and Berber, A. (2001) 'Safety and efficacy of two courses of OM-85 BV in the prevention of respiratory tract infections in children during 12 months', Chest, Vol. 119, pp.1742-1748.

Hadden, J.W. (1993) 'Immunostimulants', Immunology Today, Vol. 14, No. 6, pp.275-280.

Hanson, K.A. and Heidrick, M.L. (1991) 'Immunomodulatory action of levamisole-II. Enhancement of concanavalin A response by levamisole is associated with an oxidation degradation product of levamisole formed during lymphocyte culture', International Journal of Immunopharmacology, Vol. 13, No. 6, pp.669-676.

Haskins, R. and Kotch, J. (1986) 'Day care and illness: evidence, costs, and public policy', Pediatrics, Vol. 77, No. 6 Pt 2, pp.951-982.

Heintz, B., Schlenter, W.W., Kirsten, R. and Nelson, K. (1989) 'Clinical efficacy of Broncho-Vaxom in adult patients with chronic purulent sinusitis - a multi-centric, placebo-controlled, double-blind study', International Journal of Clinical Pharmacology Theraphy Toxicology, Vol. 27, No. 11, pp.530-534.

Jacquier-Sarlin, M.R., Dreher, D. and Polla, B.S. (1996) 'Selective induction of the glucose-regulated protein grp78 in human monocytes by bacterial extract (OM-85): a role for calcium as second messenger', Biochemistry Biophysics Research Commisssion, Vol. 226, pp.166-171.

Jadad, A.R., Moore, R.A., Carroll, D., Jenkinson, C., Reynolds, D.J., Gavaghan, D.J. and McQuay, H.J. (1996) 'Assessing the quality of reports of randomized clinical trials: is blinding necessary?' Control Clinical Trials, Vol. 17, No. 1, pp.1-12.

Jara-Perez, J.V. and Berber, A. (2000) 'Primary prevention of acute respiratory tract infections in children using a bacterial immunostimulant: a double-masked, placebo-controlled clinical trial', Clinical Therapy, Vol. 22, pp.748-759.

Keul, R., Roth, M., Papakonstantinou, E., Nauck, M., Perruchoud, A.P. and Block, L.H. (1996) 'Induction of interleukin 6 and interleukin 8 expression by Broncho-Vaxom (OM-85 BV) via C-Fos/serum responsive element', Thorax, Vol. 51, No. 2, pp.150-154.

Litwin, M., et al. (2001) 'Sródmiazszowe zapalenie nerek zwiazane ze stosowaniem immunoterapii i leków immunostymulujacych - opis 2 przypadków [Tubulointerstitial nephritis related to immunotherapy and immunostimulation: a report of two cases]', Polski merkuriusz lekarski, Vol. 11, No. 63, pp.254-258.

Lusuardi, M., Capelli, A., Carli, S., Spada, E.L., Spinazzi, A. and Donner, C.F. (1993) 'Local airways immune modifications induced by oral bacterial extracts in chronic bronchitis', Chest, Vol. 103, No. 6, pp.1783-1791. 
Maestroni, G.J. and Losa, G.A. (1984) 'Clinical and immunobiological effects of an orally administered bacterial extract', International Journal of Immunopharmacology, Vol. 6, pp.111-117.

Marchant, A. and Goldman, M. (1996) 'OM-85 BV upregulates the expression of adhesion molecules on phagocytes through a CD14-independent pathway', International Journal of Immunopharmacology, Vol. 18, pp.259-262.

Miller, S.I., Ernst, R.K. and Bader, M.W. (2005) 'LPS, TLR4 and infectious disease diversity', Nature Reviews Microbiology, Vol. 3, No. 1, pp.36-46.

Monto, A.S. and Sullivan, K.M. (1993) 'Acute respiratory illness in the community', Frequency of illness and the agents involved', Epidemiology and Infection, Vol. 110, No. 1, pp.145-160.

Monto, A.S. and Ulman, B.M. (1974) 'Acute respiratory illness in an American community', The Tecumseh study', JAMA, Vol. 227, pp.164-169.

Mora, R., Barbieri, M., Passali, G.C., Sovatzis, A., Mora, F. and Cordone, M.P. (2002) 'A preventive measure for otitis media in children with upper respiratory tract infections', International Journal of Pediatric Otorhi, Vol. 63, No. 2, pp.111-118.

Nagase, H., Okugawa, S., Ota, Y., Yamaguchi, M., Tomizawa, H., Matsushima, K., Ohta, K., Yamamoto, K. and Hirai, K. (2003) 'Expression and function of Toll-like receptors in eosinophils: activation by Toll-like receptor 7 ligand', Journal of Immunology, Vol. 171, No. 8, pp.3977-3982.

Nandi-Lozano, E., Espinosa, L.E., Vinas-Flores, L. and Avila-Figueroa, C. (2002) 'Acute respiratory infections in children attending a child day care center', Salud Publica de Mexico, Vol. 44, No. 3, pp.201-206.

Puigdollers, J.M., Serna, G.R., Hernandez del Rey, I., Barruffet, M.T. and Torroella, J.J. (1980) 'Immunoglobulin production in man stimulated by an orally administered bacterial lysate', Respiration, Vol. 40, No. 3, pp.142-149.

Renzo, M., Giovanni, R., Maria, P.F., Barbara, C., Stefano, O., Francesco, M. and Marco, B. (2004) 'Short ribosomal prophylaxis in the prevention of clinical recurrences of chronic otitis media in children', International Journal of Pediatric Otorhi, Vol. 68, No. 1, pp.83-89.

Reyes, M.E., Fernandez, A.C., Alvarez-Sala, J.L. and Alvarez-Mon, M. (2004) 'Effect of immunomodulator AM3 on the exacerbations in patients with chronic bronchitis: a systematic review of controlled trials', Revista Clinica Espanola, Vol. 204, No. 9, pp.466-471.

Rhodes, J. (1996) 'Covalent chemical events in immune induction: fundamental and therapeutic aspects', Immunology Today, Vol. 17, No. 9, pp.436-441.

Rhodes, J. (2002) 'Discovery of immunopotentiatory drugs: current and future strategies', Clinical Experiment Immunology, Vol. 130, No. 3, pp.363-369.

Schaad, U.B., Mutterlein, R. and Goffin, H. (2002) 'BV-Child Study Group. Immunostimulation ith OM-85 in children with recurrent infections of the upper respiratory tract: a double-blind, placebo-controlled multicenter study', Chest, Vol. 122, pp.2042-2049.

Selwyn, B.J. (1990) 'The epidemiology of acute respiratory tract infection in young children: comparison of findings from several developing countries', Reviews of Infectious Disease, Vol. 12, Supplement 8, pp.870-888.

Spaner, D.E., Miller, R.L., Mena, J., Grossman, L., Sorrenti, V. and Shi, Y. (2005) 'Regression of lymphomatous skin deposits in a chronic lymphocytic leukemia patient treated with the Toll-like receptor-7/8 agonist, imiquimod', Leukemia and Lymphoma, Vol. 46, No. 6, pp.935-939.

Sprenkle, M.D., Niewoehner, D.E., MacDonald, R., Rutks, I. and Wilt, T.J. (2005) 'Clinical efficacy of OM-85 BV in COPD and Chronic Bronchitis: a systematic review. COPD', Journal of Chronic Obstructive Pulmonary Disease, Vol. 2, pp.167-175.

Steurer-Stey, C., Bachmann, L.M., Steurer, J. and Tramer, M.R. (2004) 'Oral purified bacterial extracts in chronic bronchitis and COPD: systematic review', Chest, Vol. 126, No. 5, pp.1645-1655. 
Symoens, J., Veys, E., Mielants, M. and Pinals, R. (1978) 'Adverse reactions to levamisole', Cancer Treatment Reports, Vol. 62, No. 11, pp.1721-1730.

Vacheron, F., Perin, S., Kodari, E., Smets, P., Zalisz, R. and Guenounou, M. (1989) 'Immunological activities of RU-41740, a glycoprotein extract from Klebsiella pneumoniae. III. Role of LPS-like and LPS-non-related molecules', Research Immunology, Vol. 140, No. 2, pp.159-172.

Valleron, A.J. and Grimfeld, A. (1992) 'Evaluation of clinical trials of immunomodulators for prevention of recurrent respiratory infections in children', Developments in Biological Standardization, Vol. 77, pp.149-158.

Van Wauwe, J. and Janssen, P.A. (1991) 'On the biochemical mode of action of levamisole: an update', International Journal of Immunopharmacology, Vol. 13, No. 1, pp.3-9.

Weeratna, R.D., Makinen, S.R., McCluskie, M.J. and Davis, H.L. (2005) 'TLR agonists as vaccine adjuvants: comparison of CpG ODN and Resiquimod (R-848)', Vaccine, 1 August.

WHO (1998) 'Acute respiratory infections: the forgotten pandemic', Bulletin of the World Health Organization, Vol. 76, No. 1, pp.101-103.

World Health Organization (2005) 'Fact Sheet 113. Bovine spongiform encephalopathy', Available at: http://www.who.int/mediacentre/factsheets/fs113/en/print.html. Accessed on 20 July.

Zagar, S. and Lofler-Badzek, D. (1988) 'Broncho-Vaxom in children with rhinosinusitis: a double-blind clinical trial', Journal of Oto-Rhino-Laryngology and its Related Specialties, Vol. 50, No. 6, pp.397-404. 